\title{
EL DICTAMEN DE LOS HERMANOS CORONEL EN MATERIA DE “CAMBIOS Y CONTRATOS" DE 6 DE OCTUBRE DE 1517
}

\author{
JOSE M. ${ }^{a}$ GONZALEZ FERRANDO
}

\section{INTRODUCCION}

La existencia de un dictamen o «determinación» de los doctores hermanos Coronel ${ }^{1}$ en relación con una consulta formulada a principios del siglo Xvı por los mercaderes españoles residentes en Flandes sobre «cambios y otras formas de comprar,y vender" fue dada indirectamente a conocer en nuestros días por Jean-Albert Goris, al publicar en 1925 su muy interesante estudio sobre las colonias mercantiles meridionales en Amberes durante el período situado entre finales del siglo Xv y mediados del XvI, trabajo que tuvo pronto una amplia difusión entre los estudiosos de la historia económica.

Esto fue así porque en el capítulo quinto de dicha obra, en el que trata de «la moral y los negocios», recoge el texto completo de un segundo dictamen ${ }^{2}$ - ya citado en 1896 por Richard Ehrenberg ${ }^{3}$ - que a petición de los mercaderes de la colonia o "nación española» residentes en Amberes había elaborado la Universidad de París en 1530 , y de cuya traducción del latín al castellano se encargó el doctor Alvaro Moscoso, que fue uno de los

'Los denominados «doctores hermanos Coronel» $\rightarrow$ "Coroneles», como se decía en el siglo xVI - eran naturales de Segovia y se llamaban Luis y Antonio Núñez Coronel. Iniciaron sus estudios en Salamanca y hacia 1500 se trasladaron a la Universidad de París e ingresaron en el Colegio de Monteagudo, en el que Antonio llegó a ser discípulo predilecto de Juan Mair. Luis, el mayor de los dos, entró como socio en el Colegio de la Sorbona en 1509; Antonio lo hizo en 1511. Se doctoraron en teología en 1514 y 1516, respectivamente. Ambos eran de filiación nominalista. Antonio publicó numerosas obras escolásticas; su hermano Luis no fue tan fecundo y se interesó también por la física. A finales de 1517 los dos hermanos marcharon a Flandes, en donde desempeñaron un papel importante y tuvieron ocasión de trabar amistad con Juan Luis Vives. De Luis se sabe que entre 1521 y 1522 trabajaba en la Inquisición de Bruselas y que en 1527 era secretario del Inquisidor General, Alfonso Manrique, Arzobispo de Sevilla, así como que falleció en 1531. Su hermano Antonio había muerto con anterioridad. Tenian al menos otro hermano, de nombre Francisco Fernando, que se dedicó a la carrera de las armas.

' Goris (1925), pp. 503.545, y en particular pp. 510-532.

${ }^{3}$ Ehrenberg (1922), tomo 2, p. 18. 
que lo firmaron ${ }^{4}$. Y precisamente en el preámbulo de este dictamen de 1530 se hace mención a otro anterior de dicha Universidad que fue redactado en 1517 por los doctores hermanos Coronel, cuyo original y copias parecían haberse perdido. Sin embargo, ya a mediados del siglo XVI, tanto teólogos y moralistas como incluso los hombres de negocios castellanos, no sólo conocían la existencia de este primer dictamen, sino que hasta tenían copias manuscritas del mismo.

Respecto de los negociantes, Fernando Saravia ${ }^{5}$, desde la primera edición de su Instrucion de Mercaderes ${ }^{6}$ de 1544, hace referencia a que ha visto traslados del referido dictamen en manos de los mercaderes castellanos, aunquue supone que no podía ser de los «doctores Coroneles» por lo equivocada que veía su interpretación de la justificación del «lucro cesante».

Por lo que hace a teólogos y moralistas, Diego de Soto alude al dictamen que nos ocupa, también a partir de la primera edición de su tratado De Iustitia $\mathcal{E}$ Iure $^{7}$ en 1553.54 , criticando los aspectos que entiende están desenfocados de la doctrina sobre la «usura» a la sazón imperante, pero sin reproducir el comentado texto de los «doctores Coroneles».

Martín de Azpilcueta, en su Comentario resolutorio de Cambios ${ }^{8}$ de 1556 , se refiere solamente a la respuesta de los «Doctores de París», de los cuales fueron «aquellos dos renombrados hermanos Antonio y Luis Coronel», y a la reprensión que de ellos hace Soto, que es por quien conoce el asunto.

Luis López cita igualmente en su Instructorium Negotiantium ${ }^{9}$, en fecha tan tardía como 1589, la respuesta de los «parisienses doctores hermanos Coroneles» y su defensa por Azpilcueta, del que ha tomado la referencia, aunque también la conozca por Soto.

Por su parte, Francisco de Vitoria, en sus comentarios a la Secunda secundae, de Tomás de Aquino, dictados a partir del curso de 1534 y publicados por primera vez entre los años 1932 y 1934 sobre la base del texto manuscrito de los apuntes de clase tomados por un aventajado alumno, el bachiller Francisco Trigo, comenta tanto el primer dictamen de la Universidad de París de 1517, en el que participaron los «doctores Coroneles», como el segundo, que contradice las conclusiones del anterior ${ }^{10}$. A este dictamen

- Del dictamen de 1530 recogido por Goris pronto se hicieron eco dos autores españoles que lo citan con algún detalle: Ricardo García Villoslada (1938), pp. 159-160, y Ramón Carande (1943), p. 231 , completada en la 368 con la referencia a la fuente, y (1965) c (1987), pp. 345 y 529 .

5 Acerca de la atribución del nombre de Fernando a Saravia de la Calle, véanse González Ferrando (1988), pp. 218-219, y Alonso Rodríguez (1971), p. 168.

- Saravia (1544), ff. 92 v. a 93 v: y (1547), f. 57 recto y verso.

- Soto (1553-54), Libro $7 .^{\circ}$, Cuestión 5.', Artículo 5, pp. 603 y 604.

- Azpilcueta (1556), Comentario resolutorio de Cambios, núm. 34, p. 74.

9 López (1589), Libro 2., Capítulo 13, f. 347, columna 1.

to Vitoria (1934), tomo 4, Cuestión 78. ${ }^{3}$, Artículo 2. ${ }^{\circ}$, núm. 74, pp. 233-234. 
de la Universidad de París de 1530, en la versión utilizada por Goris ", van unidas unas «disensiones» de Vitoria en las que éste trata ocho nuevos casos que resuelve con criterio aún más riguroso que el mostrado por los quince doctores firmantes del dictamen, adición que, en opinión de Henri Lapeyre, no tiene nada que ver con el referido dictamen ${ }^{12}$.

En todo caso, la existencia de este primer dictamen no había caído enteramente en el olvido, puesto que ya entre 1932 y 1934 se publicaron los mencionados comentarios de Vitoria, aunque desgraciadamente sólo en latín, y a partir de 1949 las referencias al mismo se hacen cada vez más numerosas y ya en lenguas vivas. Así, en dicho año, se reimprime la primera edición de la obra de Saravia con su alusión a la «determinación» de los Coronel ${ }^{13}$; en 1952 se edita por Vicente Beltrán de Heredia nuevamente el texto del segundo dictamen de la Universidad de París, así como las «disensiones» de Vitoria ${ }^{14}$, coincidiendo casi con la publicación por Marjorie GriceHutchinson de un extracto de las preguntas y de parte del dictamen de $1530{ }^{15}$; en 1967 se da a la luz, dirigida por V. Diego Carro, una edición facsimilar bilingüe de la de 1566 del tratado De Iustitia et Iure de Soto ${ }^{16}$, a cuya crítica del dictamen de los hermanos Coronel ya se había referido Lapeyre en su obra sobre los Ruiz ${ }^{17}$ aparecida en 1955; y más recientemente, en 1985, en la obra de José Barrientos García sobre la «Escuela de Salamanca», se recoge tanto un resumen de los comentarios de Vitoria y de Soto al primero de los dictámenes como el texto del segundo ${ }^{18}$. Pero lo cierto es que, según ya ha quedado indicado, parecía haberse perdido la transcripción del dictamen o «determinación» de los doctores hermanos Coronel.

Sin embargo, una feliz casualidad hizo que al examinar en la Biblioteca Nacional de Madrid lo que por la referencia del fichero parecía ser solamente un tratado sobre los «censos al quitar», obra de cierto clérigo llamado Diego Pizarro, procedente de la biblioteca de Luis de Usoz y Río y clasificado bajo la signatura U/8.124, me encontrara encuadernado junto con este libro hasta siete memoriales o folletos más ${ }^{19}$, de los cuales cinco eran impresos

"Biblioteca de Munich, Codex bispanicus, núm. 30.

12 Lapeyre (1955), p. 314, nota 9.

13 Saravia (1949), pp. 175-176.

"Vitoria (1952), Apéndice II, pp. 113-129.

${ }^{15}$ Grice-Hutchinson (1952), pp. 38 y $120-126$ (Appendix 1), citado en Grice-Hutchinson (1979), p. 94, o (1982), p. 128, en la que alude también a la primera consulta de 1517. Por cierto que, salvo en el Apéndice, aparece siempre como año del segundo dictamen el de 1532, en lugar de 1530 .

16 Soto (1968), tomo 3, p. 603.

1: Lapeyre (1955), p. 333 y nota $110 ;$ p. 127 y notas 98 y 99.

18 Barrientos Garcia (1985), tomo I, pp. 128-129 (Vitoria), pp. 272-274 (Soto) y pp. $279-287$ (segundo dictamen).

19 Los textos amparados por la indicada signatura son los ocho siguientes:

- U/8.124 (ff. 1-72): Tractado sobre los Censos, de Diego Piçarro, clérigo de la 
y dos manuscritos, y precisamente uno de estos últimos era una copia o traslado de la hasta ahora no identificada ni localizada versión castellana del

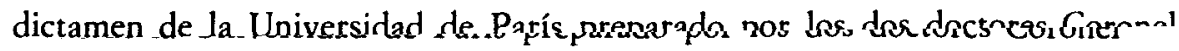
en 1517.

El presente trabajo tiene como finalidad dar a conocer el texto del repetido dictamen, precedido de una descripción de su contenido y de un comentario acerca de las opiniones en él expuestas, y completado con una reseña de las críticas a que dio lugar en el siglo xvı.

Puebla de Guadalupe. Obra impresa en Guadalupe por Francisco Díez, en 1548, y completada en Medina del Campo, en 1551, por Gulielmo de Melis, con la Portada y la Dedicatoria glosada del autor al muy reverendo señor Prior de Nuestra Señora de Guadalupe.

- U/8.1242 (ff. 73-83): Memorial sobre consejos para que su Magestad alcance lo que todos sabemos que dessea, es a saber, desterrar vicios y peccados de sus estados, y que los vassallos sean sustentados en paz y justicia, se propone lo siguiente. Dividido en cinco capitulos; anónimo y sin fecha, con una Introducción-resumen.

- U/8.124 (ff. 84.95): En este papel se trata quan dañosos son los censos perpetuos, con pacto de alquitar, como oy se usan en estos Reynos, y qual sea su justo precio; anónimo y sin fecha.

- U/8.1244 (ff. 96-135): En este papel estan recopiladas algunas leyes del derecbo comun por las quales paresce como es conforme a ellas todo lo que se a propuesto a su Magestad para desterrar vicios y peccados de sus estados y para que los vassallos sean sustentados en paz y justicia; anónimo y sin fecha, con un sumario inicial.

- U/8.1245 (ff. 222-226): Memorial sobre censos; manuscrito en latín, anónimo y sin techa.

- U/8.1246 (ff. 227-230): Discurso sobre la iustificacion de los Censos, del Licenciado Gregorio López Madera, Fiscal de su Magestad en la Chancillería de Granada; sin data.

- U/8.124 (ff. 231-249): Negociacion de Cambios; anónimo, fechado en Madrid el 15 de abril de 1633; y

- U/8.124 (ff. 250-254): Determinaciones bechas por muchos famosos doctores sobre cambios; manuscrito, redactado por Antonio y Luis Coronel en París, a 6 de octubre de 1517.

Por el salto de 86 folios que se produce entre los textos U/8.124 y U/8.124 , podría pensarse que inicialmente fueran incluso más los memoriales que estuvieran encuadernados juntos. Al propio tiempo, no parece infundado suponer que la inclusión de los textos $\mathrm{U} / 8.124^{7}$ y $\mathrm{U} / 8.124^{3}$ sea un añadido posterior, dado que solamente está numerado correlativamente el primer folio del memorial U/8.124, pues la foliación consecutiva que se les ha dado en esta nota es la que les hubiera correspondido. Respecto de la obra que da título a la entrada - U/8.124 - ha de señalarse que el licenciado Diego Pizarro recoge el texto en latín de las Extravagantes de Martín $V$ y de Calixto III, que glosa en la misma lengua, así como la Ordenanza redactada en castellano por el Prior del Monasterio de Santa María de Guadalupe, cuya glosa hace en latín. En esta Ordenanza se contienen las condiciones en que se deben hacer los contratos de censo «al quitar», basadas en las Extravagantes de los Pontífices Martín V y Calixto III, para que no ofendan a Dios por razón de usura. El úlitimo de los textos reseñados - U/8.124 - es el manuscrito del dictamen de la Universidad de París que en el presente artículo se transcribe. El penúltimo -U/8.124' - es un memorial que trata de los asientos que hacen los banqueros con el rey, de cuyo texto estoy preparando igualmente su transcripción comentada, por su interés en relación con los asientos concertados por los últimos Austrias, así como con las opera. ciones de cambio necesarias para el desartollo de tales asientos y la forma de contabilizar estas operaciones en partida doble. 


\section{LA MORAL ECONOMICA EN FLANDES A COMIENZOS DEL SIGLO XVI}

El choque de las estrictas ideas medievales en materia de moral económica sustentadas por los teólogos escolásticos, con las nuevas operaciones de préstamo, cambio y compraventa que propiciaba el desarrollo comercial y financiero que se estaba iniciando con el siglo xvi, fue motivo de continua angustia para los mercaderes de la época, que se debatían entre la prohibición de las prácticas usurarias y la necesidad de adaptarse a las nuevas corrientes financieras que les originaban escrúpulos de conciencia, ante el temor de que pudieran violar la prohibición de la usura o no respetar la correcta aplicación del justo precio.

No ha de extrañar, por tanto, que los mercaderes que formaban las colonias españolas en las plazas mercantiles de Flandes contasen con religiosos que actuaban de directores espirituales, tan necesarios en una sociedad como aquélla, impregnada de un profundo sentido de religiosidad, para orientarles no sólo en lo personal y familiar, sino también en sus dudas en materia de tratos y contratos mercantiles.

Estos escrúpulos de conciencia llevaron en 1517 a los mercaderes de la colonia española de Brujas a plantear sus dudas a su confesor, fray Andrés de Saldaña, el cual, para mayor garantía, recabó el asesoramiento de los doctores hermanos Coronel, y éstos, a su vez, las sometieron posteriormente a los doctores de la Facultad de Teología de la Universidad de París, dando lugar al dictamen o «determinación» que nos ocupa y cuyo contenido se va a examinar a continuación.

Pero previamente conviene recordar que de entre los varios títulos que distinguían los escolásticos para justificar la posibilidad de una compensación por encima del principal, los considerandos básicos eran el «riesgo" - periculum sortis—, el «daño emergente» -damnum emergens-y el «lucro cesante" -lucrum cessans-. La admisión de este último título, a la que los nominalistas se mostraban más abiertos, era la que presentaba mayores dificultades, ya que su amplia aceptación podía dar al traste con la doctrina de la Iglesia contra la «usura».

\section{CONTENIDO DEL DICTAMEN}

El texto del manuscrito presenta dos partes bien diferenciadas:

- Una primera en la que se exponen y solucionan los tres casos de «cambios» planteados por los mercaderes de la «nación» o colonia española 
de Brujas, y que firman los nueve doctores en Teología reunidos en la sacristía de la iglesia del Colegio de la Sorbona, cuyos nombres en el manuscrito y aquellos por los que hoy nos son más conocidos ${ }^{20}$ se detallan a continuación:

Manuscrito

Joan Godedte, deán de nuestra Facultad.

Guillermo de Ugena o de Cuerca ${ }^{21}$.

Pedro Tartare.

Joan de Fenario.

Joan Maoris.

Roberto Jaquitón.

Guillermo Güete.

Luis Coronel.

Antón Coronel.
Actual

Juan Godet, decano de la Facultad de Teología.

Guillermo Duchesne (de Quercu) ${ }^{21}$. Pedro Tateret.

Juan de Feynier.

Juan Mair.

Roberto Jacquinot.

Guillermo Huet.

Luis Núñez Coronel.

Antonio Núñez Coronel.

- Una segunda con una extensión superior en un 50 por 100 a la de la primera, y firmada ya sólo por los dos hermanos Coronel, que está integrada por sus «declaraciones» o explicaciones para aclarar y ampliar lo anteriormente expuesto respecto de los indicados tres casos, más la adición de la venta «al fiado», como corolario del segundo caso, y del controvertido supuesto en aquellos tiempos del «atrancar de ferias», obtenido mediante la consideración conjunta de los casos segundo y tercero, así como la de diversos casos singulares de compra y reventa de una misma mercancía.

\section{a) Dictamen conjunto de los nueve doctores de la Universidad de París}

El primero de los casos o «cambios» planteados equivale a lo que hoy denominaríamos una transferencia de fondos entre dos plazas extranjeras - de París a Roma, por ejemplo-, a fecha estipulada, realizada por un mercader o banquero por orden y cuenta de un hombre de negocios.

Para nuestros doctores está claro que la cantidad o «ventaja» razonable que cobre el mercader o banquero por sus servicios en la remesa de fondos está justificada por el trabajo y riesgo que comporta no sólo el traslado del

${ }^{20}$ García Villoslada (1938), pp. 371-433.

"No he logrado identificar con plena seguridad al Guillermo de Ugena (o Guillermo de Cuerca) que aparece en el manuscrito como firmante del mismo, aunque con un relativo grado de incertidumbre me inclino a pensar que puede ser Guillermo Duchesne, también llamado latinizadamente Guillermo de Quercu. 
dinero, sino la penalidad en que podría incurrir si no estuvieran disponibles los fondos en la fecha convenida.

El segundo «cambio» supone el anticipo de una cierta cantidad de dinero hecho por un mercader o banquero en una plaza - París, por ejemplo- a otra persona que necesita los fondos para emplear en su negocio y que se compromete a devolverlos en el plazo de dos meses en otra plaza - por ejemplo, Lyón-, a cuyo efecto libra una letra a favor del mercader o banquero que le provee de fondos y sobre su factor de esta última plaza.

Según los doctores, las mismas razones que justificaban en el primer caso que el mercader o banquero percibiera una "ventaja» o comisión por sus servicios son igualmente válidas para este segundo «cambio», siempre que lo que lleve por su intervención no exceda de lo acostumbrado.

Por último, en el tercer «cambio» se presenta otra operación de anticipo de fondos semejante a la del segundo, pero en la que el plazo se alarga hasta seis meses.

Estiman los doctores que por razón del mayor plazo de la operación y, por consiguiente, del aumento del «lucro cesante» que esto representa para el mercader o banquero que anticipa los fondos, la comisión o «ventaja» a aplicar debe ser superior en atención al mayor tiempo que tarda en recuperar su dinero para reinvertirlo en su actividad mercantil o bancaria, pero siempre dentro de lo que es costumbre a juicio de hombres prudentes.

\section{b) Ampliación de los hermanos Coronel al dictamen}

Respecto del primer «cambio», los hermanos Coronel insisten en que aun cuando el mercader o banquero no fuese penalizado por no tener situados los fondos en la fecha convenida, siguen siendo válidas las demás razones expuestas para justificar el cobro de una comisión, como hoy se diría, aunque en tal caso pudiera ser algo menor.

En cuanto al segundo «cambio», aportan una justificación complementaria consistente en asimilarlo al primero, señalando que así como en éste el mercader o banquero hace como de «llevador" de los fondos de París a Roma, en el segundo caso hace como de «traedor» del dinero de Lyón a París. Por otra parte, refutan el que se pudiera pensar que, al igual que en el primer caso el mercader o banquero cobra por trasladar los fondos de París a Roma, en el segundo caso el que recibe el dinero en París y lo entrega en Lyón sería el que debiera cobrar la comisión al mercader o banquero que se lo facilitó, recalcando que la persona que recibió el dinero en París no lo hizo por complacer o servir al mercader o banquero que se lo entregó, sino en atención a que lo necesitaba para sus negocios, por lo que las dos operaciones son radicalmente distintas. 
Mediante la presentación conjunta de los «cambios» segundo y tercero, los Coronel elaboran un cuarto «cambio» que resulta ser lo que en el siglo xvI se denominaba «saltar», «atrancar» o «trascabalgar de ferias»; esto es, "cambiar» los fondos para mayor plazo del que media entre dos ferias consecutivas, saltándose como mínimo la feria intermedia que hubiera sido el vencimiento normal del «cambio», lo que constituye una de las operaciones más reprobadas por teólogos y moralistas de la época.

En su opinión, si tanto en el segundo como en el tercer caso se puede considerar lícito el pago de una «ventaja» o comisión, también lo sería cuando el plazo del «cambio» fuera tal que se salte la primera feria o incluso la sucesiva o sucesivas; y precisamente por razón del «lucro cesante» la «ventaja» habría de ser mayor en tanto en cuanto el plazo igualmente lo fuera.

Como corolario del segundo caso, confirmado también por el tercero, presentan los hermanos Coronel la venta a crédito o «al fiado", en la que justifican la exigencia de un mayor precio sobre el de contado por el retraso en el cobro de la venta, ya que el mercader está dejando de ganar — «lucro cesante»- al no poder poner en movimiento el importe aplazado.

Aclaran la justificación del «atrancar ferias» y de la venta «al fiado» más cara que al contado con los siguientes «argumentos»:

- Son sólo operaciones lícitas para el mercader o banquero que esté en condiciones de reinvertir inmediatamente el producto de tales operaciones en otras nuevas propias de su actividad; no lo son para el prestamista, ya que se consideraba que éste no era un oficio o trabajo lícito.

- Un mercader o banquero prefiere tener su dinero colocado en operaciones rentables a tenerlo inactivo en metálico, pues de esta forma no obtiene ningún rendimiento.

Para salvar la aparente contradicción entre lo expuesto por ellos y lo dicho por el Papa Alejandro III al arzobispo de Génova en su Decretal In civitate tua ${ }^{22}$ de que sólo se podría vender más caro al fiado que al contado cuando se pudiera suponer que al tiempo del pago la mercancía hubiera subido de precio y valiera tanto como se puso de precio a la venta al fiado, los doctores Coronel agregan un tercer «argumento» en el que manifiestan que el Papa presuponía que los tales mercaderes no estaban en condiciones de poder reinvertir los fondos en el momento en que los cobrasen, por lo que no se produciría pérdida para ellos aunque aplazaran el cobro. $Y$ aseguran que en este sentido se han expresado los teólogos y canonistas en relación, al pare-

"Corpus iuris canonici (Decretales), Libro V, título XIX, capítulo VI (X5, 19, 6). 
cer, con las Decretales Consuluit ${ }^{23}$, del pontífice Urbano III, y Naveganti ${ }^{24}$, de Gregorio IX.

Para concluir sus explicaciones introducen un último apartado o caso que denominan «del comprar y revender», en el que suponen que un mercader compra una mercancía que revende inmediatamente por más precio a otro mercader, sin haberla modificado en lo más mínimo. En estas circunstancias, estiman que si tanto el revendedor como el comprador son personas que entienden del producto de que se trata, la operación es lícita. Por el contrario, si el comprador no es entendido y el revendedor le engaña, éste debe restituirle lo cobrado en exceso; por igual razón, si el comprador se aprovecha de la necesidad del revendedor y le paga menos de lo que vale, debe restituirle también.

Los dos hermanos Coronel completan esta solución con seis «reglas» que son otras tantas variantes del problema de la compra y reventa en un corto espacio de tiempo de una misma mercancía:

- La necesidad de una sola persona no permite que lícitamente se le venda más cara una mercancía; cuando la necesidad es general, sí puede hacerse lícitamente.

- La posibilidad de poder vender la mercancía a mejor precio en otra parte, no es razón suficiente para que se venda por más precio del que otro fuese a pagar.

- La venta a precio por debajo de lo que vale una mercancía a otro mercader que no está en principio interesado en adquirirla, no obliga a hacer restitución de la diferencia entre ambos precios.

- Cuando el coste de una mercancía haya resultado ser superior al precio de venta, no es ilícito venderla por el susodicho coste.

- A igualdad de calidad, no es ilícito que un mercader obligue a una persona a comprar algo que pensaba adquirir de otro si, al propio tiempo, quiere comprar otra mercancía que sólo tiene el primer mercader.

- Una mercancía recién comprada se puede revender lícitamente a otro mercader por más precio del pagado, siempre que dicho mercader lo acepte $u$ ofrezca de buena gana.

${ }^{23}$ Corpus iuris canonici (Decretales), Libro V, título XIX, capítulo X (X5, 19, 10).

${ }^{24}$ Corpus iuris canonici (Decretales), Libro V, título XIX, capitulo XIX (X5, 19, 19). 


\section{COMENTARIOS AL DICTAMEN}

Sorprendentemente para la época, la amplia aceptación que del concepto de «lucro cesante» hacen los nueve doctores firmantes del dictamen - casi todos ellos nominalistas-, y muy particularmente los dos hermanos Coronel, como justificación del cobro de una compensación por lo que se dejaría de ganar ${ }^{25}$ por un mercader o banquero ante la imposibilidad de realizar otras operaciones lucrativas para las que estuviera preparado, viene a coincidir con la moderna noción del «coste de oportunidad» ${ }^{26}$, que implica la elección entre varias posibilidades simultáneamente excluyentes de colocación de los fondos disponibles.

Ello nos presenta a los nueve doctores de la Universidad de París - pero en especial a los Coronel, sin duda por su contacto con Flandes, en cuyos puertos se estaba desarrollando un intenso intercambio comercial y financiero- como unos auténticos adelantados en materia de moral económica, aunque para los escolásticos del siglo xvi constituyera una interpretación en exceso laxa y permisiva del «lucro cesante», puesto que esta interpretación no se generalizará hasta que el papel del dinero adquiera un mayor relieve y el factor tiempo empiece a ser tenido en consideración.

En efecto, de haberse aceptado tal criterio, se podría haber percibido - alícitamente y sin cargo de conciencia", como dicen nuestros doctoresuna «ventaja» o compensación por casi todas las clases de «cambios» entonces utilizadas y, cosa que era aún peor considerada, esta «ventaja» podría ser función creciente del plazo de dichas operaciones, lo que hubiera supuesto tanto como dar por lícito el tan denostado por los escolásticos «saltar», «atrancar» o «trascabalgar de ferias» sin reconocer la «usura»-interés, en términos actuales- que encerraba el cambio claramente en estos casos.

Esto resultaba inconcebible en los comienzos del siglo xvI, y por eso el dictamen fue duramente criticado a lo largo del siglo por diversos autores, para los que el «lucro cesante» sólo podía aceptarse en contados casos y con toda suerte de restricciones. Concretamente, los escolásticos aceptaban como lícito el «cambio» sobre la "próxima feria» o "a una feria», pues consideraban que la compensación percibida no contenía implícitamente «usura» -es decir, interés- y, sin embargo, rechazaban los «cambios» que saltaban ferias, por entender que en tales casos la correspondiente mayor compensación ya incluía "usura», lo que para ellos era de todo punto intolerable. De hecho, si hubiesen admitido que el curso o tipo del cambio «a la próxima

${ }^{25}$ En todo caso dejan muy claro nuestros doctores que ha de tratarse de una uganancia verosímil» -real- y no de "ganancia incierta», pues esta última no la aceptarían como justificación del «lucro cesante» por considerarla «ilícita».

${ }^{26}$ De Roover (1971), p. 89. 
feria» disimulaba el interés que lógicamente se incluía en él por tratarse

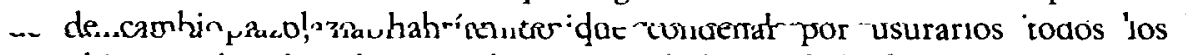
"cambios», salvo los de contado, y esto hubiera dado lugar a gravísimos problemas comerciales y financieros. Resumimos a continuación las críticas procedentes de los autores citados al principio del artículo, basadas en estas ideas.

Vitoria, que apenas admite el «lucro cesante» si no es cuando equivale a un verdadero "daño emergente» ${ }^{27}$, se refiere a este dictamen en relación con su postura totalmente negativa a autorizar una mayor compensación por el retraso en los pagos mediante los «cambios de atrancar ferias», saltándose una o más. Como en su dictamen los nueve doctores de la Universidad de París determinan que, por razón del «lucro cesante», era justo y lícito recibir por «atrancar ferias» un lucro mayor en las segundas ferias que en las primeras, Vitoria estima que los doctores parisienses, entre los que se encontraba su maestro Juan de Feynier, así como Juan Mair y «ambos Coroneles». se engañaron no en la doctrina, sino en los hechos porque los mercaderes no los plantearon correctamente. Y como prueba de ello, en su interés por salvar la autoridad de los doctores, señala que los mismos mercaderes de Flandes, «no estando seguros, tornaron a enviar el mesmo caso a Paris y que los doctores que antes determinaron que era licito ${ }^{28}$, determinaron lo contrario», puesto que el «atrancar de ferias» es usurario ${ }^{29}$.

Soto, aunque no tan riguroso como Vitoria, rechaza igualmente que sea de justicia percibir alguna ganancia por razón del retraso en los pagos derivado de que se salten las ferias; es decir, prorrogando hasta las terceras o cuartas ferias, dejadas a un lado y diferidas las primeras que se presenten. Y destaca que de la opinión de poder exigir una mayor compensación en estos casos fue causa principalmente la «determinación» o dictamen de algunos parisienses en el año 1517, con el cual respondiendo a tres preguntas de los mercaderes, en la tercera respuesta les concedieron que con razón podían cobrar ganancia a causa del «lucro cesante», de los trabajos y de la industria. Por este motivo añadieron que si, dejadas pasar unas ferias, el pago se difería para otras, en este caso cuanto más largo fuera el plazo más se podría cobrar. Indica Soto, por último, que los corifeos de este negocio fueron los «dos hermanos Coroneles», de no despreciable erudición y fama; pero en esto, en opinión de los mismos mercaderes, se apartaron de su propósito, tanto de hecho como de derecho, y erraron por no haber considerado más atentamente que por razón del objeto este «cambio» era vicioso, con lo cual

${ }^{27}$ García Villoslada (1938), p. 159.

${ }^{28}$ Aunque Vitoria indica que fueron los mismos, lo cierto es que el único doctor que intervino en ambos dictámenes fue el escocés Juan Mair.

29 Vitoria (1934), tomo 4, pp. 231-234. 
ofrecieron a los mercaderes unat ocasión manifiesta para la usura, con grave daño para la conciencia de los mercaderes ${ }^{30}$.

Azpilcueta es también de criterio estricto aunque comprensivo, pero como no parece haber tenido conocimiento directo del dictamen sino por intermedio de Soto y, por otra parte, tiene gran admiración por los hermanos Coronel - de los que señala que sus obras y consejos algún tiempo le aprovecharon-, ante la reprobación por Soto de lo que en la respuesta de los doctores de París se dice respecto de que los mercaderes puedan llevar más si aplazan el cobro hasta las segundas ferias, que si solamente aguardasen hasta las primeras; y más si lo retrasaran hasta las terceras que si lo hacen hasta las segundas, puesto que la compensación será mayor cuanto más dejen verosímilmente de ganar, procura exculparlos indicando que no es de creer que «tan doctos Doctores de tan gran Universidad» se refiriesen a este «cambio», pues aun los estudiantes de pocos años saben que «comprar o trocar mas caro por mas largo plazo, es usura». Aventura por ello que puedan referirse al caso, aceptado por la doctrina, del cambiador que trata en mercancías y que por prestar a otro tiene que dejar de negociar con sus mercancías; e incluso lo amplía manifestando que aunque no trate en otra mercancía fuera de sus cambios, pero si por prestar deja de tratar en ellos, siendo lícitos, podrá llevar la compensación de la ganancia que por prestar deja de obtener ${ }^{31}$.

López se muestra muy estricto en cuanto a la opinión que le merece la respuesta de los «parisienses doctores hermanos Coronel» acerca de la licitud de percibir mayores emolumentos por alargar el plazo de los «cambios», en cierto modo prácticamente suscrita por Azpilcueta, y que conoce por las referencias de Soto y del propio Doctor Navarro. Se debe esto a la publicación entonces reciente - 1571 - de la Decretal In ean ${ }^{32}$, del Papa Pío V, sobre los "cambios»" en la que prohibe terminantemente que se realicen éstos de otra manera que no sea para las primeras ferias, rechazando por completo el abuso de «cambiar» a feria intercalada, a la segunda o tercera feria, o a otros plazos ${ }^{34}$.

Finalmente, y por haber sido uno de los primeros en ocuparse de este

${ }^{30}$ Soto (1968), tomo 3, pp. 602, col. 1, a 606, col. 1 .

3 Azpilcueta (1965), Comentario resolutorio de Cambios, núm. 34, pp. 53-55.

${ }^{32}$ Corpus iuris canonici (Liber Septimus Decretalium), Libro Il, título XI, capítulo I (VII2, 11, 1).

${ }^{33} \mathrm{La}$ traducción y comentario de esta Decretal, así como su texto latino, constituyen el Capírulo 12 del Libro cuarto, dedicado a los «Cambios», de la Summa de Tratos, y Con. tratos de Tomás de Mercado desde la segunda edición de 1571: Mercado (1571), tomo 2, ff. 53-60 -n realidad son 12 folios, motivo por el que posiblemente no se han numerado a partir del 53, que, por cierto, figura con el número 57-; Mercado (1587), ff. 208 219, y Mercado (1977), pp. 454-472.

34 López (1589), pp. 347-348. 
asunto, ha de citarse a Saravia, de criterio también bastante riguroso, el cual, por tener conocimiento de que muchos mercaderes castellanos encontraban tan de su agrado el dictamen o «determinación» que lo habían copiado al comienzo de sus libros mayores, lo condena pensando que no puede ser fruto de la Universidad de París ni de los «doctores Coroneles», sino obra de un impostor. Para ello hace un amplio estudio acerca de la consideración del «tiempo» en los «cambios» que por la forma en que centra el problema se reproduce a continuación ${ }^{35}$ :

«Y para mas declaracion de la consideracion del tiempo en los cambios. Nota que el tiempo entre la data del dinero y su restitucion se puede considerar en tres maneras. La primera el tiempo necessario entre la data y paga del dinero, y esto es licito porque no se puede hazer esta paga en un momento y ha de passar el tiempo que es menester para yr de un lugar a otro; $y$ assi no se tiene respeto al tiempo sino al lugar. La segunda que en el tiempo aya diversidad de precios. De tal manera que una misma cosa que se vende en el principio de un tiempo puede tener un precio; y en el medio otro y en el fin otro, y esto tambien es licito considerarse porque esto no es por el tiempo sino por la cosa en el tiempo. La qual unas vezes vale mas en un tiempo que en otro, como el marco de plata de Londres, algunas vezes vale mas otras menos, y lo mismo passa en Flandes en las coronas y otras monedas segun la falta o abundancia de moneda ay en la plaça. La tercera el tiempo en el qual la moneda (dada) esta ociosa y sin provecho en poder del que la recibe y tener consideracion a este tiempo y ganar por el, es usura; y deste tiempo hemos siempre hablado que no se tenga consideracion $\mathrm{ni}$ respecto al tiempo en los cambios que se hizieren; $\mathrm{y}$ por esto lector guardate de unas determinaciones, ca de los cambios que andan entre mercaderes diziendo que son de la Universidad de Paris, y de los dotores Coroneles. Lo qual yo no creo porque yo no he visto los originales, y los traslados he visto en poder de muchos y que no concuerdan: antes cada uno esta de su manera. Sospecho que algun sycophanta usurero las devio componer para favor de sus usureros y usuras; porque personas tan doctas no darian tal determinacion, como la del tercero

${ }^{35}$ Saravia (1544), ff. $92 \mathrm{v}^{\circ}$ a $93 \mathrm{v}^{\circ}$, y Saravia (1547), f. 57 recto y verso. El texto que se ofrece es una refundición de las dos ediciones de la obra; las palabras incluidas entre paréntesis * (...) $)$ no figuran en la edición de 1547 , y las que van entre corchetes «[...]» no aparecen en la de 1544. 
caso, o cambio, donde determinan que el que da al cambio cien coronas por seys meses, que puede llevar mas interesse ${ }^{36}$ que si las diesse por dos meses, atento que el oficio de cambiador es tratar con su dinero, y que se priva de su dinero por aquel tiempo, y que en recompensa de aquello que dexa de ganar puede llevar interes teniendo respecto al tiempo, lo qual es falsissimo porque si esto fuese licito nunca se daria caso [en que] en el cambio pudiese aver usura, pues no la puede aver sino por la consideracion del tiempo, y como parece por lo que en este capitulo he provado, no se puede tener consideracion al tiempo para que se lleve mas o menos; y por la misma razon el cambiador podia dar dineros a catorze por ciento, o de otra manera porque tambien en estos casos se priva de ganar con su dinero, y no se puede tener respecto al lucro cesante quando el mercader, o cambiador por su voluntad contrata y quiere tratar mas por esta via que por otra, como bien provado en el capitulo. xj. del lucro cessante, y el Papa no habla en caso que venga daño, o en el que no avia de guardar su mercaderia, porque sino la avia de guardar y la avia de vender, que daño le podia venir assi que sea cuya fuere aquella determinacion, ella es falsa y favorecedora de usuras y por esto fuy avisado que muchos mercaderes la tienen escrita en el principio de su libro de caxa para hazer sus usuras arguyendo de alli que siendo licito en el cambio llevar interes por el tiempo, que tambien sera licito vendiendo la mercaderia al fiado, y es buena la consequencia, sino que assi como el antecedente es falso, tambien lo es el consequente, por esso te quise avisar letor porque no te engañes con aquellos magnificos titulos de Universidad de Paris y de Coroneles.»

\section{EL MANUSCRITO Y SU TRANSCRIPCION}

El dictamen está copiado en un cuadernillo de papel hoy amarillento, del que ocupa cinco hojas de unos $20 \times 29$ centímetros, numeradas del folio $\mathrm{j}$ al v en «cuenta castellana», llenando en su totalidad las diez páginas resultantes.

Su estado de conservación es bastante bueno, aunque el margen de la primera hoja está ligeramente desgastado, por lo que algunas palabras de la

${ }^{36}$ El término «interesse" tenía el significado de remuneración, compensación, cmolu. mento, etc., y no el actual de «interés», que entonces se denominaba «usura». 
primera página aparecen incompletas o faltan. La tinta aún no se ha decolorado en exceso.

La letra es clara y no abundan los borrones que oculten texto, pero la ortografía resulta muy insegura, de forma que una misma palabra puede aparecer escrita de distintas maneras, a veces con pocas páginas o incluso líneas de separación. Al propio tiempo, se halla muy influenciada por el latín; igualmente se aprecia una notable tendencia a sustituir la «n» final de palabra por «m», sobre todo en las últimas páginas del manuscrito.

En la copia es frecuente el uso de abreviaturas, pero todas ellas son las utilizadas corrientemente. También son muy numerosas las contracciones, algunas de las cuales incluso son bastante inusuales.

Para la transcripción del documento, al que se le ha conservado su fecha original de 6 de octubre de 1517, referida al calendario Juliano, se han seguido las pautas que se indican a continuación:

- Se ha respetado la grafía del manuscrito, incluso la defectuosa, a excepción de las mayúsculas y minúsculas, que han sido utilizadas con criterio actual.

- Se han resuelto las abreviaturas y mantenido todas las contracciones, por muy inusuales que resultasen.

- Cuando pudiera parecer que existe error de transcripción o errata de imprenta en alguna palabra, se ha señalado con «(sic)».

- En aquellos casos en que no tengo seguridad de haber interpretado correctamente el texto, lo indico con «(?)».

- Las palabras o partes de palabras completadas se incluyen entre corchetes $\ll[\ldots] »$.

- Las palabras que he considerado sobraban en el texto del manuscrito se han incluido entre paréntesis «(...)».

- Las escasas palabras que están repetidas se han eliminado, lo que igualmente se ha hecho con las tachadas y anuladas en el manuscrito.

- Se ha conservado la «cuenta castellana» cuando ésta es la forma numeral utilizada en el manuscrito para expresar cantidades o fechas.

- Ante la práctica ausencia de puntuación del texto, lo he puntuado tal como creo que hoy se hubiera hecho, asumiendo el riesgo de no interpretar fielmente el fresco lenguaje coloquial del documento, a menudo confuso, pero muy rico en matices. 


\section{DICTAMEN DE LA UNIVERSIDAD DE PARIS AMPLIADO POR LOS HERMANOS CORONEL}

[f. $1 \mathrm{r}^{\circ}$ ] Siguese una determination hecha por muchos famosos doctores de Paris sobre ciertas maneras de cambios y contratationes que accostumbran hazer los mercaderes.

\section{Muy nobles y virtuosos Señores.}

El verano pasado, estando yo en la villa de Gante, por las manos del Reve[rendo] y muy devoto Padre fray Andres de Saldaña, confesor de vuesas mercedes, me fueron [a mi?] estos Articulos presentados, los quales contenian maneras de contratos, ansi $e$ [ $n$ lo que] toca a los cambios como cerca de otras formas de comprar y vender, para quel $\mathrm{d}$ [octor] Luis Coronel mi hermano y io, vistos y examinados los Articulos, dixesemos si con seguridad de buena concientia podrian los mercaderes usar de las dichas maneras y formas y contratos.

En verdad, señores, donde estava el Reverendo Padre frai Andres, muy escusado y superfluo es nuestro parezer, porque su sufficientia y celo basta para cosa de mayor importantia. Mas el, por su bondad, tubo por bien de nos communicar los dichos Articulos y, con el deseo que tiene de sanar vuestras concientias, no se contento de con solo su parezer: el doctor Luis Coronel y yo muchas veces conferimos sobre los dichos Articulos y disputamos entre nosotros la materia, y parezionos por la gratia de Dios aver hallado la conclusion verdadera en este negocio.

Mas por ser el caso tan principal, no contentos con solo nuestro parezer, acordamos que viniesse yo a Paris a communicar los dichos Articulos con algunas personas de nuestra sancta Facultad de Teologia, adonde despues de venidos se scribieron los dichos Articulos, interpretando el castellano en latin, y se presentaron ansi tresladados a las personas mas principales de la Universidad de Paris, e yo y el doctor Luis Coronel, mi hermano, disputamos la materia con cada uno dellos en particular. Concluimos que todos nos juntasemos en nuestro famatissimo Colegio de Sabona ( $s i c$ ) en la sachrestia de nuestra yglesia, adonde proposimos como de parte de la noble y muy venerable nascion de Spaña que reside en el Condado de Flandes, en la villa de Brujas, nos fueron presentados aquellos Articulos e que yo ni el doctor 
Luis Coronel, por maior seguridad, no quesimos decir nuestro parescer hasta averlo communicado. con elloş y nor_esto lę̧_sunlicamos di[xiere]n (?) su parescer. /

[f. 1 v. ${ }^{\circ}$ ] Deliberaron segun sus antiguedades y a todos nos parescio las tres formas y maneras de contratos que despues se pornan, ser justas y licitas, y poderse hazer, y sin ningun cargo de concientia. Dimos muchas gratias a Dios por aver avido en un caso tan principal y tan deseado tal conclusion, por parescer de tan excelentes varones y personas, las quales eran por todos ix. doctores. Y scriptos los articulos en pergamino, se firmaron.

\section{Año Udxviiijo ${ }^{37}$ (?)}

Siguense los Articulos con su determination puestos en castellano claro y destintamente.

\section{Siguese el primer caso o cambio.}

En la ciudad de Paris esta una persona que se llama Juan o Pedro, la qual tiene voluntad de hir a Rroma o a otra parte; y porque teme que por ventura le robaran en el camino, viene a Francisco, mercader o banquero, y diçele: yo te ruego que recibas de $\mathrm{mi}$, aqui en Paris, c. escudos de oro y me des una cedula de cambio para algun amigo tuyo, o factor, que esta en Rroma o en otra parte, para que alla me dem por virtud de la dicha cedula c. escudos. Francisco, mercader o banquero, diçe que en ninguna manera le dara la dicha cedula si no le diere cv. escudos o ciij. escudos; y la raçon porque quiere el dicho Francisco quel dicho Pedro le de v. o iij. de ventaja, est porque queda el dicho Francisco obligado azer diligentia et despensas, por si o por su factor o amigo, para imbiar o tener en Rroma o en otra parte, persona que de al dicho Pedro c. escudos a dia cierto e determinado. Juntamente queda el dicho Francisco obligado a perder algo sobre cada corona sino hiziere dar al dicho Pedro en Roma o en otra parte, a cierto e determinado dia, los dichos c. escudos. Finalmente se conciertan desta manera: Pedro da a Francisco, mercader o banquero, en Paris o en tra (sic) parte, cv. escudos o ciij. escudos y rescibe del una letra de cambio por virtud de la qual el dicho Pedro recibira en Rroma, de su amigo

"Este año, que interpreto como 1519 , correspondería a la versión castellana del dictamen, ya que la fecha del original en latín es de 1517. 
o factor de Francisco, c. escudos solamente. Es agora la question si Francisco, mercader o banquero, puede llevar licitamente aquellos v. o iij. de ventaja.

\section{Solution del primer caso o cambio.}

Respondemos a este caso que, teniendo consideration a las deligentias y costas quel dicho Francisco ha de hazer por su persona o por su factor o amigo, conviene a saber: tener o imbiar los dineros a Rroma o otra parte de persona que de los dichos [f. 2 r. $^{\circ}$ ] dineros a cierto y determinado dia a Pedro; / ansi mesmo, considerando el peligro a que se ofreçe si no se cumple su cedula en Rroma o en otra parte, decimos que licita e justamente, e sin cargo de cientia ${ }^{38}$ ( sic), puede el dicho Francisco llevar alguna cosa de lo capital e principal. Y si preguntaredes: ¿quanto mas?, conviene a saber, si puede llevar cinco o tres por ciento, decimos questo se pode medir segun se acostumbra a llevar y segun juicio de buenos y prudentes ombres.

\section{Siguese el segundo caso o cambio.}

En la ciudad de Paris, o en otra parte, esta una persona que se llama Juan, la qual tiene falta de dineros para sus negoçios, por lo qual viene a Alverto, mercader o banquero, e dizele: yo te ruego que me des en Paris o en otra parte $c$. escudos y io te dare una cedula de cambio para mi factor o amigo, para que te los de en Leon o en otra parte dentro de dos meses; y esto haze Juan a Alverto de su propia voluntad e sin que Alverto le fuerce. Responde y dice Alverto: en ninguna manera hare lo que dices sino fuere tu letra de cambio tal que por virtud della aya de recebir en Leon o en otra parte cv. escudos o ciij. escudos, y esto por las ratones (sic) siguientes: la primera, porque tengo de hazer diligentia en imbiar tu letra de cambio a Leon o a otra parte; la segunda, porque he de tener un factor o amigo en Leon o en otra parte, queste cite a tu factor o amigo para que me page (sic) los dineros que yo aqui te do. Finalmente, ellos se conçiertan desta manera: que Alverto da a Juan en Paris o en otro lugar c. escudos o su valor y recebi del una letra de cambio por virtud de la qual en Leon o en otra parte rescibira cv. escudos

\footnotetext{
${ }^{j 6}$ Debe decir «conciencia».
} 
o ciij. escudos. Es agora la duda e question si Alverto, mercader o banquero, puede justamente e sin cargo de concientia llevar del capital o principal v. o iij. escudos.

\section{Solution del segundo caso o cambio.}

Respondemos que, teniendo consideration a la diligentia que Alverto ha de hazer en imbiar la letra de cambio a Leon o a otro lugar, ansi mesmo que le cumple tener en Leon un factor que solicite a su factor o amigo de Juan que pague los dineros quel dicho Juan recebio en Paris, decimos que licita e justamente puede Alverto, e sin cargo de concientia, llevar algo mas de lo capital $y$ principal; y el quanto mas se a de medir segum la costumbre e juicio de buenos y prudentes ombres. /

En la ciudad de Paris o en otro qualquier lugar esta una persona que se llama Guillermo, la qual tiene nescesidad de dineros. Viene a Pabitio, mercader o banquero, y dicele: yo te ruego que me des aqui c. escudos de oro o su valor y io te dare una letra de cambio para un mi factor o amigo, por virtud de la qual recibiras en Leon dentro de vj. meses otros c. escudos o su valor. Pavitio responde que en ninguna manera dara los dichos $c$. escudos si la cedula de cambio no fuere tal que por virtud della reciba en Leon o en otro lugar cvj. escudos o ciiij ${ }^{\circ}$. escudos mas. Seria contento, dize Pabicio, con cv. escudos o ciiij ${ }^{\circ}$. escudos, si dentro de dos meses pudiese cobrar mis dineros; y la razon porque Pabicio, mercader o banquero, quiere llevar mas quando pasa mas tiempo antes que cobre sus dineros, es porques mercader o banquero, y el officio del mercader o banquero es usar de su dinero o trocar con ello, o comprando o dando a cambio. Siguese quanto despues de mas tiempo a de cobrar Pabitio sus dineros que da a Guillermo, tanto por mas spatio de tiempo se priva Pabicio de usar de su arte o officio o instrumento, el qual officio y arte esta aparejado Pabitio de usar quanto es de su parte, donde paresçe quel dicho Pabicio resçibe por la dicha privation o impedimento algun daño, por la qual cosa justo es que Guillermo aga alguna recompensation al dicho Pabitio, mercader o banquero. 


\section{Solucion del tercero cambio o caso.}

Respondemos que, por raçon del interesse o daño que, en Paris o en otra parte, Pabitio rescibe en privarle o empedirle el uso o egercitio de su arte o officio, justamente y sin cargo de concientia, puede Pabicio llevar no solamente algo de mas de lo principal o capital, mas aun mas que llevaria si dentro de dos meses oviese de cobrar sus dineros, mayormente si por la cobranca de los dichos dineros el factor o amigo de Pabicio se detiene en Leon o en otro lugar por mayor spacio de tiempo. Y el quanto mas ha de ser segun se acostumbra llevar o segun juicio de buenos ombres. Esto que se contiene en estos tres casos scriptos e sus solutiones, es lo que confirmaron los doctores como paresce por la scriptura en pergamino, los nombres de los quales son los que se siguem: Maestre Joan Godedte, dean de nuestra Facultad; maestro Guillermo de Ugena o de Cuerca (?); maestro Pedro Tartare; maestro Juan de Fenario, de la Orden de los Predicadores; maestre Juan Maoris; maestre Roberto Jaquiton; maestre Guillermo Guete, de la Orden de los Menores; maestre Luis Coronel y maestre Anton Coronel. /

[f. $3 \mathrm{r}^{\circ}$ ] Yo e mi hermano Luis Coronel pornemos agora algunas declarationes cerca de lo arriba contenido porque dificultad en su entendimiento no aya.

Cerca del primer caso o cambio no conviene decir cosa alguna porques claro e la solution del tiene verdad e justicia.

Cerca de la solution del segundo caso conviene notar que otras ratones (sic) se suelen traer para probar que se puede hazer sin cargo de concientia. Conviene a saber que ansi como en el primer caso Predro (sic), mercader o banquero, es casi llevador o portador de los dineros de Juan desde Paris o de otro lugar a Rroma o a otra parte, en el segundo caso Alverto sea como traedor de los dineros de Juan desde Leon a Paris; y quantas mas causas y rationes ocurieren, tanto mas sim cargo de concientia se podra el dicho cambio hacer. Mas nosotros quisimos poner las ratones (sic) que segun la natura y condition del contrato occurem, y esto porque fuese la solution general y no encurriessem muchas condictiones que fuera confusion y pudieram causar escrupulos de concientia. 
De la solution del segundo caso juntamente con la del tercero

Siguese manifiestamenta (sic) el atrancar de ferias ser licito y justo y poderse haçer sin cargo de concientia, porque manifiesta cosa es si puede un mercader o un banquero llevar 4. o 3. por ciento quando dentro de dos meses que dio sus dineros en Paris o en otra parte a Juan, los ha por letra de cambio de cobrar en Leon o en otra parte. Tambien puede sin cargo de concientia llevar 3. o 4. pcr ciento quando despues de seis meses que dio sus dineros en Paris los ha de cobrar en Leon, segum las solutiones del segundo y tercero caso. Notorio es y manifiesto, que puede un mercader concertarse ansi y desta manera con la persona a quien da los dineros en Paris o en otro lugar: si por tu letra de cambio me los hicieres dar en Leon o en otra parte dentro de dos meses, darme has 2. o 3. por ciento mas; si dentro de seis meses, darme as 3. o 4. Y sin duda ninguna este quarto caso no est otro sino el segundo y tercero todos juntos, y no se puede en latin ni en otra lengua poner ni explicar este atrancar de ferias sino juntando los dos casos ya nombrados; conviene a saber: el tercero y el segundo, y por esto no se puso aparte por evitar prolixidad tam superflua.

De la solution del segundo caso se sigue quel mercader que vende lanas o pimienta o otra mercaduria al fiado, y si la vendiese al contado, la daria por diez ducados; mas vendiendola al fiado, dala por xi. ducados. Lo puede haçer liçitamente, presupuesto quel dicho mercader este presto y aparejado quanto es de su parte; conviene a saber: que no quedara por el para usar de exercitar los dichos diez ducados comprando con ellos alguna mercaduria o dandolos a cambio, por lo qual parece que al dicho mercader le valdria agora mas de diez ducados de contado que no le valem los xi. ducados que ha de recebir de aqui a dos meses o tres; y la

[f. 3 v. ${ }^{\circ}$ ] raçon desto es el dicho, / por careçer al presente de sus dineros, privarse y empedirse en todo o en parte de exercitar su arte o su officio, por lo qual paresçe quel dicho mercader recibe algun daño, por donde se muestra que la persona que compra al fiado le deve haçer alguna recompensa, ques la raçon del tercer caso.

\section{Siguese un argumento.}

Y si alguno me dixiere que desta manera se provara ser licita la usura o logro por quel usurero o legrero (sic) podra decir a 
aquel a quien presta: amigo, yo te presto diez ducados, los quales me pagaras y restituiras de aqui a mediaño; mas porque en este mediaño yo sere privado o impedido, por averte prestado estos dineros, de exercitar mi officio, conviene a saber que no tiene que prestar o no tiene tanto dinero para prestar, quiero me des algo mas. Respondemos quel argumento no concluye y la raçon es porquel prestar en quanto prestar no es officio mediante del qual se puede ganar cosa del mundo porque aquello esta defedido (sic) por lei y derecho, natural y humano y divino, mas el officio del mercader o banquero o cambiador es officio mediante el qual pueden los ombres licita e justamente ganar, y por esto puede un mercader o banquero quando en todo o en parte el exercitio de su officio, porque a causa del tal impedimento recebe daño que con pecunia se pueda recompensar, llevar algo de abantaja. Mas el logrero, aunque por prestar ansi sus dineros se impida de emprestarlos a otro, no deve por esso de pedir ni demandar mas de lo que presta por la racon dicha: combie[ne] a saber, quel prestar en quanto prestar no es officio mediante el qual puede nenguno llevar mas de lo principal, i por esto, aunque mempreste (sic) ansi sus dineros, no senpide ( $\mathrm{sic}$ ) de usar de su officio o arte por cujo (sic) uso o exercicio no puede ganar cosa alguna como el mercader o banquero haze.

\section{Segundo argumento.}

$Y$ si alguno me dixiere: yo quiero probar queste mercader o banquero no recibe daño quando se defiere la restitucion o paga por mas spacio de tiempo; para lo qual provar, yo pregunto a este mercader o banquero qual queria el mas, tenerse su dinero o darmelos a mi por 6. meses, para que por mi letra de cambio los aya en Leon o en otra parte. Si dixiere, como esta claro, que quiere mas lo segundo con alguna habantaja, siguese que no recibe en ello ningun daño, porque de otra manera mas se los queria tener que darmelos a mi para que se los restituia dentro de medio año por mi letra de cambio (dentro) en Leon. Digo este argumento, conviene distinguir esta propusicion: este mercader quiere o deve querer mas darle sus dineros que tenerselos en su poder o darmelos sin que le de algo de abantaja; y digo que mas quiere tenerse los dineros que darmelos sin la bantaja que io le doi. Estonces digo que puede ser que quiera mas darmelos, y en darmelos ansi como me los da; conviene a saber: con la bantaja que yo le do; yo 
confieso questonces no reciba daño el mercader porquel (dinero) estara recompensado con lo que yo le doi mas de su principal. $Y$ el que arguie a de provar quel mercader en darme estos dineros, e sin que yo le de algo mas, no recebe daño; y esto no se puede probar, porque lo contrario pruebam manifiestamente las ratones (sic) arriba puestas. /

Y si alguno dixiere quel Papa espresamente diçe en el capitulo in civitate extra de usuris que ningun mercader puede llevar por su mercaduria, quando la vende al fiado, mas que quando la vende al contado, excepto quando est verisimile que al tiempo que se a de pagar, si se guardase hasta estonces, valdria tanto en quanto se fia; conviene a saber: yo te vendo una mercaduria que vale al contado $x$. ducados, mas porque te la do fiada, quiero que me des por ella xij. ducados. Dice el Papa queste contrato est iniquo e injusto, aunque no se puede probar ser usurario, excebto si esta mercaduria la avia io de guardar por dos meses, despues de los quales la dicha mercaderia baldria xij. ducados, questonces bien se puede vender fiada por doce ducados. Paresce manifiestamente questa determination del Papa sea contra nuestra resolution: a este argumento decimos quel Papa presupuso en el dicho capitulo questos mercaderes no recibam daño ninguno en carescer, por el tiempo en que fiavan, de su dinero, porque por ventura no estavan aparejados o a comprar con ellos o darlos a cambio. $Y$ digo que ansi se a de entender el dicho capitulo porque cosa cierta est que, si daño rescebian, que podian llevar mas por su mercaduria de diez ducados, como est opi[ni]on de los teologos e canonistas en el capitulo de pluribq extra de usuris.

$Y$ en esta scriptura, si huviesse de poner todos los argumentos que se puedem haçer, aunque la determination fuesse muy averiguada, ni a nosotros nos occurian todos ni menos se podiam en mayor scriptura comprehender, y por esto pusimos solamente tres que nos parescen ser tales que de la solution dellos se puede colegir la solution de otros muchos.

\section{Siguese del comprar y revender.}

En la villa de Brujas residen muchos mercaderes que tienen por officio comprar lanas que vienen de Spaña o de Inglaterra e la 
speçeria que viene de la India. Acontece muchas veces que Juan. mercader, compra de Pedro, mercader, $x$. sacas de lana a diez ducados la saca, y el dicho Juan las vende luego a un otro tercero mercader, sin mejorarlas ni guardarlas por tiempo alguno. por doce ducados o xj. las sacas (sic); est agora la question si Juan al dicho precio puede vender las dichas sacas.

\section{Siguese la solution.}

Decimos que aqui conviene ver dos cosas: la primera, quanto a lo que toca a comprar las dichas sacas; lo segundo, quanto toca a venderlas.

$\mathrm{Y}$ decimos que puede ser que Juan engañe a Pedro en el precio de las dichas lanas porque puede ser que Pedro no tiene por officio, o no est cosa que pertenesçe a su officio, conoscer el valor de las lanas; ansi mesmo puede ser que Pedro conozca que sus lanas valen mas de lo que Juan da por ellas, mas constreñido con nescesidad, esle forcado de vender su mercaderia a menos precio porque Juan no le quiere dar mas por ella, y clara cosa es que en tal caso

[f. 4 v. ${ }^{\circ}$ ] Juan engaña a Pedro y es obligado / a restituir a Pedro la summa en que le engaño. Mas si entrambos, ansi Juan como Pedro, tienem officio oppertenece (sic) a su officio cognoscer el valor de las lanas, y piensa Pedro que vende bien su mercaduria dando sus sacas a diez ducados por cada una, y Juam piensa que las podra vender por mas, dicimos que no haçe engaño a Pedro, porque en tal caso devemos interpretar la voluntad de Pedro ser contenta de haçer gratia a Juan de lo de mas que sus sacas valen, si ansi fuere que valem mas, y si piensa que las podra vender por mas, dicimos que no haçe engaño.

Quanto a lo que toca a lo segundo, decimos que tambien puede Juan engañar al tercero mercader a quien rescibe ${ }^{39}$ (sic) sus sacas; conviene a saber: si el comprador no cognosçe lo que compra ni pertenesce a su officio cognoscer el valor de la lana, o si compra por mas de lo que vale la lana porque tiene della nescesidad e Juan no se la quiere dar por el justo precio sino por mas de lo que vale. Decimos que en tal caso Juan est obligado a restetuir aquel a quien sus sacas revende de quanto est el engaño que le haçe. Mas si entrambos a dos, ansi Juan como el terçero que le

"3* Debe decir "revende». Se trata de una crrata que el copista ha cometido $-y$ corregido- varias veces, pero que en este caso se le ha pasado rectificar. 
compra las sacas, tratan en lanas y a su officio pertenesçe conosçer el valor de la lana, e segum su humana congetura nenguno piensa que engaña al otro, decimos que sin cargo de concientia puede Juan la saca que compra por $\mathrm{x}$. ducados venderla por $\mathrm{xj}$. ducados, aunque no la aya mejorado, porque en tal caso interpretase la voluntad del comprador ser haçer gratia a Juan de lo que da demas del valor de la mercaduria; conviene a saber: la mercaduria vale $\mathrm{x}$. escudos ${ }^{43}$ o ducados; da por ella Martin $\mathrm{xj}$.; puestas las conditiones ia dichas, respondemos que interpretamos la intention e voluntad de Martin ser haçer gratia a Juan de una corona o ducado, e si alguno dixiere que qualquier hombre de buen juicio sin letras dira otro tanto, confesamos ser ansi en la realidad de la verdad; e en muchas cosas un hombre prudente puede dar tan buen parescer sin letras como un letrado, mas chrehemos que no se deve diçir ni dar otra resolution al caso puesto, quanto a lo que toca al dicho revender.

Mas, cerca desta materia, conviene notar ciertas Reglas.

La primera est que la nescesidad que tiene mi proximo de $\mathrm{mi}$ mercaderia no est causa sufficiente para que mi mercaderia le pueda vender por mas que a otro que no tiene della tanta nescesidad. Mas la nescesidad que tiene la Republica de mi mercaderia porque aia maior multitud de hombres que antes o por otras causas que puedem ocurrir, puede ser causa porque yo pueda, sin cargo de conçientia, vender mi mercaderia por mas de lo que la deva vender si la Republica no tuviese la dicha necesidad. Y la razon est la nesçesidad de la Republica haçer la mercaderia de maior valor e la nesçesidad de una particular persona. Quiero poner desto exemplo: en el Condado de Flandes pongamos que ay ogaño maior numero de traperos e personas que haçen paños quel año pasado, do clara cosa est tener a esta causa la Republica de Flandes maior nesçesidad de lanas que no el año pasado; decimos que la dicha nesçesidad de la Republica haçe las lanas valer mas.

\section{Segunda Regla.}

Sea mi mercaderia provechosa a mi proximo por quel la llevara a vender a parte adonde ganara mucho con ella o por otra causa:

\footnotetext{
to Al escudo también se le llamaba ucoronax.
} 
no est raçon sufficiente para que io ge (sic) la pueda vender por mas de lo que se deve vender a otro. /

[f. $\left.5 \mathbf{r}^{\circ}\right]$

Tercera Regla.

Un mercader tiene nesçesidad de dinero e un otro mercader no tiene necesidad de la mercaderia del primero. Conviene a saber: Juan tiene nesçesidad de dineros por lo qual le est forçado vender sus lanas por menos de lo que valen; Pedro est otro mercader que no tenia intention ni voluntad de comprar las lanas de Juan. Presupuesto quel valor de cada saca sea $x$. ducados, el las da a Pedro por 9. ducados e Pedro no est contento de dar por ellas mas de 9. ducados, decimos quel dicho Pedro no est obligado ha hacer restitution alguna al dicho Juan.

\section{Quarta Regla.}

Puede ser quel justo o reguroso valor de una mercaderia sea ix. ducados; mas yo, que la tengo de vender, comprela mas cara o he hecho en guardarla muchas costas, de manera que si yo la vendo por solos $\mathrm{x}$. ducados sere danificado, e para no reçebir daño tengola de vender por doçe duçados. Deçimos que licitamente e sin cargo de concientia la puedo vender por xij. ducados.

\section{Quinta Regla.}

Viene un mercader que se dice. Andres a la feria de Medina, el qual ha de comprar sedas e lanas, el qual queria comprar las sedas de Martin e no ay otro que tenga lanas sino io en la dicha feria. Decimos que licita e justamente puedo constreñir a Andres que compre de mi las sedas e no de Martin, presupuesto que mis sedas sean tam buenas como las de Martin, e de otra manera no le vendere las lanas.

\section{Sexta Regla.}

Yo compre de un mercader que se diçe Nicubio unas sacas de lana o otra mercaderia ayer o oi por $x$. ducados, el qual mercader tiene por officio tratar e conosçer lanas e la dicha mercaderia. Por ventura por se despachar de su mercaderia, o porque piensa que la vende bien, damela a mi por $\mathrm{x}$. ducados. El mesmo dia 
que io la compre, sin mejorarla ni guardarla, vendola a un otro mercader o trapero que tiene por officio tratar e conoscer lanas, por xi. ducados, y es ansi en la realidad de la verdad que ni el ni yo pensamos que engañamos ni somos engañados. Decimos quel dicho contrato se puede hacer sin cargo de conçientia por la raçon puesta arriba en el caso del revender.

Y suplicamos que qualquiera que leiere esta Regla lea tanbien la raçon que possimos en la solution del dicho caso. Otras muchas Reglas se pueden poner, mas chrehemos que todas son a vuesas mercedes notorias, e si estas aqui puestas no lo heran, serlo han de aqui adelante; y si lo heran, sera esta scriptura una breve confirmation.

Cerca de la solution del primer caso o cambio, noten que quando el mercader o banquero no quedase obligado a pagar cosa alguna sobre cada escudo cuando fuesse ansi que su cedula no se cumpliese en Rroma o en otra parte, aun podria por las otras raçones alli puestas llevar mas de lo capital o principal, quanto mas ofreciendose al dicho peligro o tomando sobre si la dicha pena, mas no tanto. /

[f. $5 \mathrm{v.}^{\circ}$ Tanbien conviene notar que por las raçones por las quales probamos la forma del primer cambio ser licita e justa, podria alguno querer probar la manera del segundo cambio ser justa, diciendo que si la raçon por quel mercader o banquero en el primer cambio quiere llevar a dos por ciento, est porque tiene de haçer diligentia e costas en imbiar o proveher en Rroma o en otra parte de los dineros que le da Juan en Paris. Ansi ni mas ni menos el dicho Juan en el segundo caso o cambio est obligado ha haçer la diligentia e costas en inbiar o proveher los dineros en Leon que en Paris rescibe de Alberto, por lo qual pareçe que antes Alverto, mercader o vanquero, est obligado a dar a Juan uno o dos por ciento; a lo menos est obligado a no llevarle mas de lo quel le da en Paris.

Decimos a este argumento que se ofrecqo (sic) ques insuficiente e aparente e no esistente, porque Juan no rescibio de Alverto en Paris c. escudos por haçer placer o servitio al dicho Alverto, mas solamente por complir sus nescesidades, e si Alverto por darle sus dineros a cambio tiene de haçer diligentia o costa en imbiar o llevar la letra de cambio de Juan a Leon, justo es que Juan se lo page (sic) tambien. Juan no va a Rroma ni imbia en el primer caso por recebir sus dineros, de manera que la raiz ni fundamento 
total ni parcial de ir Juan a Rroma no est recebir alla los dineros que dio en Paris a Pedro: mas en el _segundo_casn_o.camhio la raiz o fundamento total o parcial de ir o imbiar Alverto, mercader o banquero, a Leon, est por cobrar los dineros que dio a Juan en Paris, de manera que bien considerado mucha differentia va del primero al segundo.

Nosotros, señores, suplicamos que ningun mercader nos juzge (sic) por esta scriptura por personas de rota o habierta concientia, porque no es nuestra intention de haver interesse ni complacer a ninguno ni lisongear, mas solamente decir la verdad por seguridad de vuestras concientias, e chrehemos que no est otra vuestra intencion, e si alguno se moviere a causa de lo dicho ha haçer algun contrato elicito, sanguis etq super caput etq; i tanbien si alguno para colorear alguna mala contratation nos alegare en esta scriptura, lo qual no chrehemos que avra ninguno questo aga, si el tal no hiçiere en esta vida penitentia dello, le acusaremos dello delante el trono de Jesuchristo nuestro Redemptor el dia del Juicio como a persona que tomo ocasion de mal haçer por laver ${ }^{41}$ (sic) dicho ombre con buena conçientia lo que piensa ser verdad. E suplicamos a vuesas mercedes que nenguno nos enoje por lo dicho, e si oviere alguno que quisiere impunar o reprobar lo contenido en esta scriptura, e nos lo quisieredes haçer saber, recebiremos dello señalada merced: e si el dixiere bien, nosotros nos emendaremos; e si mal, procuraremos de emendarle.

Ansi mesmo, si oviere algun mercader que no creiere ser verdad lo contenido en esta scriptura, aconsejamosle que con tal concientia no haga lo que aqui se contiene, porque si haçe contra su concientia ofendera a Dios. E si en otra qualquier cosa se quisieren vuesas mercedes servir de nosotros, aqui o en Spaña o en otra parte, nos of reçemos a vuestro servitio con todas nuestras fuercas. E Dios vuestras muy nobles e muy virtuosas personas guarde e prospere por muchos tiempos. De Paris e de Servona (sic), a 6. dias del mes de otubre de 1517. años.

Maestre Anton Coronel e Maestre Luis Coronel.

"Esto es, «le haber» o «haberle». 


\section{BIBLIOGRAFIA}

Alonso RodRíguez, Bernardo (1971 y 1977): «Monografias de moralistas españoles sobre temas económicosm, en Repertorio de las Ciencias Eclesiásticas en España, Salamanca, tomo 2, pp. 147-181, y tomo 6, pp. 143-187.

ANDRÉs, Melquiades (1957): La teología española en el siglo XVI, Biblioteca de Autores Cristianos, Madrid (2 vols.).

AzPilcuetı, Martín de (1556): Manual de Confessores y Penitentes, que clara y brevemente contiene, la universal y particular decision de quasi todas las dudas, que en las confessiones suelen occurrir de los pecados, ábsoluciones, restituciones, censuras, E irregularidades. Compuesto por el Doctor Martin de Azpilcueta Navarro Catbedratico Iubilado de Prima en Canones, por la orden de un pequeño, que en Portuguez bizo un padre pio de la pijssima Provincia de la Piedad. Acrescentado agora por el mismo Doctor con las decisiones de muchas dudas, que despues de la otra edicion le ban embiado. Las unas de las quales van insertas so esta señal * las otras en cinco Comentarios de Usuras, Cambios, Symonia mental, Defension del proximo, De burto notable, E irregularidad. Con su Reportorio copiosissimo, Andrea de Portonarijs, Salamanca.

- (1965): Comentario resolutorio de Cambios, Consejo Superior de Investigaciones Científicas, Madrid.

Ballerini, Pietro (1747): De Jure Divino et Naturali circa Usuram libri sex, Thoman Colli ex Typographia S. Thomae Aquinatis, Bolonia, 2 tomos en 1 vol.

Barrientos García, José (1985): Un siglo de moral económica en Salamanca (1526-1629). I. Francisco de Vitoria y Domingo Soto, Universidad de Salamanca, Salamanca.

Böнm-Bawerk, Eugen von (1986): Capital e Interés, Fondo de Cultura Económica, Mé. xico, 2.* ed. española.

BROEDERSEN, Nicolaus (1743): De usuris licitis et illicitis vulgo nunc compensatoriis et lucratoriis secundum jus naturale, divinum veteris atque novi Testamenti, ecclesiasticum et civile; ac justa doctrinam sanctorum, vetertsmque patrum, theologorum, ac juris tum canonici tum civilis peritorum; nec non usum onnium saeculorum et plurimarum regionum. Libri XI, Leyden.

Carande Thovar, Ramón (1943, 1947 y 1967): Carlos $V$ y sus Banqueros, Revista de Occidente, Madrid, 1943 (tomo 1); 1. ${ }^{\text {a }}$ ed., Sociedad de Estudios y Publicaciones; Madrid, 1965 (tomo 1); 2." ed. corregida y aumentada; SEP, Madrid, 1947 (tomo 2) y 1967 (tomo 3), 1. ${ }^{2}$ ed.; Editorial Crítica, Madrid, 1987 (3 vols.), 3." y 2." eds.

Clavero, Bartolomé (1984): Usura. Del uso económico de la religión en la bistoria, Tecnos, Madrid.

Corpus iuris cononici emendatum et notis illustratum Gregorii XIII Pont. Max. iussu editum Libro VII Decretalium et Io. Pauli Lancelotti institutionibus adauctum (1776): Typographia Regia, Turín (2 vols.).

EHRENBERG, Richard (1922): Das Zeitalter der Fugger. Geldkapital und Creditverkebr im 16. Jahrbundert, Gustav Fischer, Jena, 1896 (2 vols.), 1.` ed.; 1912 (2 vols.), 2." ed., y 1922 (2 vols.), 3." ed.

García Villoslada, Ricardo (1938): La Universidad de Paris durante los estudios de Francisco de Vitoria, O.P. (1507-1522), Universidad Gregoriana, Roma.

GonzÁlez Ferrando, José $M^{a}$ (1988): «De las tres formas de llevar "cuenta y razón" según el licenciado Diego del Castillo, natural de Molina», en Revista Española de Financiación y Contabilidad, Madrid, vol. XVII, núm. 55, enero-abril, pp. 183-222.

GorIs, Jean-Albert (1925): Etude sur les Colonies Marchandes Méridionales (Portugais, Espagnols, Italiens) à Anvers de 1488 à 1567. Contribution à l'bistoire des débuts du capitalisme moderne, Librairie Universitaire, Lovaina (reproducción fotográfica de 1967).

Grice-Hutchinson, Marjorie (1952): The School of Salamanca. Readings in Spanish monetary theory, 1544-1605, Clarendon Press, Oxford.

- (1978): Early Economic Thought in Spain, 1177-1740, George Allen \& Unwin, Londres.

- (1982): El pensamiento económico en España (1177-1740), Editorial Crítica, Madrid.

Lapeyre, Henri (1955): Une Famille de Marchands: les Ruiz. Contribution à l'étude du commerce entre la France et l'Espagne au temps de Pbilippe II, SEVPEN, París. 
López, Luis (1589): Instructorium Negotiantium duobus contentum libris, Cornelio Bonardo, Salamanca.

Mercado, Thomas de (1569): Tratos y Contratos de Mercaderes y Tratantes discididos y deierminados, por el Padre Presentador Fray Thomas de Mercado, Mathías Gast, Salamanca, $1 .^{\mathrm{a}}$ ed.

- (1571): Summa de Tratos, y Contratos. Dividida en seys libros. Añadidas a la primera addicion, muchas nuevas resoluciones. $Y$ dos libros enteros, como paresce en la pagina siguiente, Hernando Díaz, Sevilla (2 tomos en 1 vol.), 2." ed.

- (1587): Summa de Tratos, y Contratos. Dividida en seys libros. Añadidas a la primera adicion, muchas nuevas resaluciones. $Y$ dos libros enteros, como parece en la pagina siguiente. $Y$ un indice copiosissimo, por orden de Alphabeto, Fernando Díaz, SeviIla, 3." ed.

- (1977): Suma de Tratos y Contralos, Instituto de Estudios Fiscales, Madrid (2 vols.), refundición de la 1." y 2." eds.

Molina, Luis (1981): La teoría del Justo Precio, Editora Nacional, Madrid (edición preparada por Francisco G. Camacho).

Moore Candejera, Eduardo (1956): La moral en el siglo XVI y primera mitad del XVII. Ensayo de sintesis bistórica y estudio de algunos autores, Facultad de Teología de Granada, Granada.

Nelson, Benjamin (1969): The Idea of Usury. From Tribal Brotherhood to Universal Otherbood, The University of Chicago Press, Chicago y Londres, 2." ed. ampliada.

Noonan, John T. (1957): The Scholastic analisis of Usury, Harvard University Press, Cambridge (Mass.).

Piçarro, Diego (1548): Tractado sobre los Censos. Tractado muy necessario y provechoso, a las Consciencias, sobre los Censos al quitar, E otros. Con la glosa de las Extravagantes de los Pontifices Martino V \& Calixto iij. Nuevamente hecho por el Licenciado Diego Piçarro Clerigo, de la Puebla de Guadalupe. Francisco Díaz, La Puebla de Guadalupe; concluido por Gulielmo de Milis, Medina del Campo, 1551.

Roover, Raymond de (1970): «La pensée économique de Jean Mair, professeur à la Sorbonne et à l'Université de Saint-André en Ecosse (début du XvI' siècle)», en Journal des Savants, abril-junio, pp. 65-81.

- (1971): La pensée économique des Scolastiques. Doctrines et Métbodes, Institut d'Etudes Médiévales, Montreal y París.

SARAviA DE la CALle, Fernando (1544 y 1547): Instrucion de mercaderes muy provechosa. En la qual se enseña como deven los mercaderes tractar, y de que manera se ban de evitar las usuras de todos los tractos de ventas $E$ compras. Assi a lo contado como a lo adelantado, $y$ a lo fiado. $Y$ de las compras del censo al quitar, y tractos de compañia, y otros muchos contratos. Particularmente se babla del tracto de las lanas. Tambien ay otro tractado de cambios. En el qual se tracta de los cambios licitos y reprobados. Nuevamente compuesto por el doctor Saravia de la Calle Beronense, Pedro de Castro, Medina del Campo, 1." y 2." eds.; Joyas Bibliográficas, Madrid, 1949, reimpresión de la edición de 1544 .

Soto, Domingo de (1553.54 y 1556): De Iustitia E Iure Libri decem, Andrés de Portonari, Salamanca, 1.* y 2." ed. corregida y aumentada.

- (1967-68): De Iustitia et Iure Libri decem. De la Justicia y del Derecho en diez libros, Instituto de Estudios Políticos, Madrid ( 5 vols.), edición facsimilar de la publicada en 1556, con versión castellana de Marcelino González Ordóñez, O. P., y una Introducción histórica y teológico-jurídica por Venancio Diego Carro, O.P.

Vitoria, Francisco de (1932-34): Comentarios a la Secunda secundae de Santo Tomás, Biblioteca de Teólogos Españoles, Salamanca ( 5 vols.), edición preparada por Vicente Beltrán de Heredia, O. P.

- (1952): Comentario al Tratado de la Ley. Fragmentos de Relecciones. Dictámenes sobre Cambios, Consejo Superior de Investigaciones Científicas, Madrid, edición preparada por Vicente Beltrán de Heredia, O.P. 